\title{
Short term properties of High Calcium Flyashbased Geopolymer binder
}

\author{
R.Manickavasagam and G.Mohan kumar \\ Research Scholar, PRIST University, Thanjavur, INDIA. \\ Professor of Civil Engineering Arunai Engineering College, Thiruvannamalai, INDIA.
}

\begin{abstract}
The past decades of research is diverted primarily in making concrete without cement or atleast partially replacing by suitable alternatives. For its availability and problems associated with, flyash has been given priority to use in concrete in high volume or total replacement of cement resulting in geopolymer concrete using activated flyash of low calcium type as the source material. However, few are dealt on the high calcium flyash that too mainly on achieving the required compressive strength and not much on the short term engineering properties like consistency and setting characteristicseven though itis essential to establish the time available for placing, compaction and transport of geopolymer. Therefore, a fundamental study on the setting characteristics and strength development of high calcium flyash based geopolymer with varying concentration of Sodium hydroxide(8-14M), varying liquid ratios (1.5-3.0) of the activator and curing at ambient and $65^{\circ}$ Ctemperature is made.It is observed that the consistency of flyash based geopolymer increases with increase of concentration of $\mathrm{NaOH}$ and is not at all influenced by the liquid ratios considered but, the setting time is reduced by oven curing obviously. Also, the mortar strength is atleast $10 \%$ more for hot curing than ambient curing.
\end{abstract}

Keywords: Geopolymer, flyash, source material, activator, consistency, setting time

\section{Introduction}

The demand for concrete is increasing day by day due to its versatility. But, the environmental issues concerned with concreteparticularly with the production of cement by the $\mathrm{CO}_{2}$ emission and the exploitation of natural resources lead to environmental degradation. Therefore, there is a need to find an alternative to cement. In 1980s, steps were taken to develop geopolymer concrete (GPC)without cement by polymerization.Geopolymer is an inorganic alumino-silicate compound, synthesized from source materials mostly byproducts like flyash, GGBS and rice husk ash. Calcined clay, kaolinitic clay, lateritic clay, volcanic rocks, mine tailings, red mud, metakaolin and other industrial wastes are also under consideration (Joseph Davidovits, 2011).But to date utilization of flyash is limited inspite of the recommendations made by Indian codes (IS: 4031 Part-4, 1988). By its availability in abundance and problems in storing, flyashhas high potential in using it as a source material for the production of GPC.There are many issues pertaining to the quality parameters of the Indian flyashes, potential of chemical activation, feasibility of adopting the newer milling systems such as vibration and attrition milling, and the need for converting the flyash grains to submicro crystalline particles thereby, significantly altering their properties and behaviour (Anjan Chatterjee, 2010).

Being very fine in particle size, if not managed well, can become airborne leading to the environmental hazards. Hence, the management of flyash is the urgent need and utilization of flyash other than high volume flyash concrete is the need of the hour. Further, Most of the reports specifically deal with the development of GPC for compressive strength. Indian specification (IS: 3812-1981) has several features for using flyashes.

Flyash rich in silica and alumina reacts with alkaline solution and forms aluminosilicate gel that acts as the binding material and by thermal activation produces GPC. The blend of sodium hydroxide and sodium silicate or potassium hydroxide and potassium silicate solution, termed as alkaline solution is mixed with source material like flyash and provides alkalinity needed to liberate the $\mathrm{Si}$ and $\mathrm{Al}$ and possibly with the additional source of silica (sodium silicate). The parameters that influenceare ratio of alkaline liquid-to-flyash (by mass), concentration of sodium hydroxide $(\mathrm{NaOH})$ solution in molarity, ratio of sodium silicate solution-to-sodium hydroxide solution (by mass), curing temperature, curing time and curing method.Consistency of geopolymer plays a major role in the workability based on the additional water requirements and also setting properties will be useful for assigning the mixing time and rest period. However, only limited studies were reported (Mallikarjuna Rao and Gunneswara Rao,2015)on these fundamental properties of Geopolymer. Most of the works reported are based on low calcium flyash based GPC(Joseph Davidovits,1994; Djwantoro Hardjito et al, 2008 andYellaiah et al, 2014)and only very few experimental investigation were made on the performance of class C(high calcium)flyash based GPC (Shankar Sanni and Khadiranaikar, 2012 and Ashley Russell et al, 2015)that too based on the strength development of GPC. 
Neyveli Lignite Corporation (NLC) is a lignite based unit generating power through major thermal Power stations and annually produces 1.20 million tons of high calcium flyash (ASTM class C). As the high calcium flyash is more cementitious compared to low calcium flyash, an experimental study is initiated for promoting high calcium flyash based GPC by making a preliminary study on its setting characteristics.

\section{Experimentation}

High calcium flyash (ASTM Class C) is obtained from the Neyveli Lignite Corporation (NLC). For comparison, ordinary Portland cement (OPC 43 grade) is also tested for its properties. The chemical composition and physical properties of the flyashand cement procured for the research are given in Table 1.The flyash and the commonly available sodium hydroxide (Analytical grade in pellets form with $98 \%$ purity) and sodium silicate solution (with $\mathrm{Na}_{2} \mathrm{O}=12 \%, \mathrm{SiO}_{2}=30 \%$, and water $=58 \%$ by mass) in combination is used as the alkaline activator. The molarity of $8 \mathrm{M}, 10 \mathrm{M}, 12 \mathrm{M}$ and $14 \mathrm{M}$ are considered for $\mathrm{NaOH}$. The activator/flyash ratio by mass is taken as 0.35 and the liquid ratio of the activating solution as 2.5. For instance, $10 \mathrm{Molar} \mathrm{NaOH}$ consists of $10 \times 40=400 \mathrm{gm}$ of Solid $\mathrm{NaOH}$ per litre of solution where, 40 is its molecular weight. The mass of $\mathrm{NaOH}$ solids is measured to be $314 \mathrm{gms} / \mathrm{kg}$ of the solution. Similarly, the details for other molarities of $\mathrm{NaOH}$ are presented in Table 2 (Rajamane NP and Jeyalakshmi, 2014 and Rangan, 2008). The NaOH solution is prepared 24 hours prior to use, to cool it at room temperature. The $\mathrm{NaOH}$ solution thus prepared is mixed together with Sodium silicate solution to get desired alkaline solution.

Table 1 Chemical composition and physical properties

\begin{tabular}{|l|l|l|l|l|l|}
\hline \multirow{2}{*}{ No } & \multicolumn{2}{|l|}{ Chemical composition (\%mass) } & \multicolumn{2}{l|}{ Physical properties of flyash and cement } \\
\cline { 2 - 3 } & Elements & Flyash & OPC43 & \multicolumn{2}{l}{} \\
\hline 1 & $\mathrm{SiO}_{2}$ & 47.60 & 22.60 & Type of flyash & ASTM class C \\
\hline 2 & $\mathrm{Al}_{2} \mathrm{O}_{3}$ & 21.40 & 04.30 & Specific gravity & 2.24 \\
\hline 3 & $\mathrm{Fe}_{2} \mathrm{O}_{3}$ & 07.80 & 02.40 & Fineness & $325 \mathrm{~m}^{2} / \mathrm{kg}$ \\
\hline 4 & $\mathrm{CaO}$ & 11.90 & 64.40 & Source from & NLC, Neyveli \\
\hline 5 & $\mathrm{MgO}$ & 01.80 & 02.10 & Type of cement & OPC 43grade \\
\hline 6 & $\mathrm{SO}_{3}$ & 02.80 & 02.30 & Specific gravity & 3.14 \\
\hline 7 & $\mathrm{Na}_{2} \mathrm{O}$ & 00.70 & 00.04 & Fineness & $315 \mathrm{~m}^{2} / \mathrm{kg}$ \\
\hline 8 & $\mathrm{~K}_{2} \mathrm{O}$ & 00.82 & 00.02 & Consistency & $29.5 \%$ \\
\hline 9 & $\mathrm{TiO}_{2}$ & 01.88 & - & Initial setting time & $36 \mathrm{minutes}$ \\
\hline 10 & $\mathrm{LOI}$ & 03.30 & 02.20 & Final setting time & $320 \mathrm{minutes}$ \\
\hline
\end{tabular}

Table 2 Mass of $\mathrm{NaOH}$ solids in various molar solutions

\begin{tabular}{|l|l|l|l|}
\hline No & $\begin{array}{l}\text { Molarity of } \\
\text { NaOH }\end{array}$ & $\begin{array}{l}\text { Mass of NaOH solids per } \\
\text { litre of solution(gm) }\end{array}$ & $\begin{array}{l}\text { Mass of NaOH solids per } \\
\text { kg of NaOH solution(gm) }\end{array}$ \\
\hline 1 & $8 \mathrm{M}$ & 320 & 262 \\
\hline $\mathbf{2}$ & $10 \mathrm{M}$ & 400 & 314 \\
\hline 3 & $12 \mathrm{M}$ & 480 & 361 \\
\hline 4 & $14 \mathrm{M}$ & 560 & 404 \\
\hline
\end{tabular}

\section{Consistency Of Geopolymer}

The consistency of the geopolymer past made with class $\mathrm{C}$ flyash is determined as per Indian code (IS: 4031 Part-4, 1988) for Portland cement paste, using Vicat's apparatus.Cementwith water and flyash with alkaline solution are respectively considered for making the binder paste. Constituents of alkaline solution are shown in figure 1. Preparing a trial paste with alkaline solution and testing with varying percentage is done until the amount of alkaline solution necessary for making up the standard consistency is obtained. This procedure is repeated for varied molarities $(8-14 \mathrm{M})$ of Sodium hydroxide and liquid ratios 1.5 to 3.0. The variation in the standard consistency for various molar concentration and liquid ratio is presented in figure 2 .

\section{Setting Time of Geopolymer Paste}

The quantity of alkaline binder is taken as $85 \%$ of normal consistency. The flyash and activator solution are placed in the mixer bowl and mixed for five minutes. The Geopolymer paste is cast into Vicat's mould in two layers with proper tamping and finishing. This is then placed for oven curing at an elevated temperature of $65^{\circ} \mathrm{C}$. For every 15 minutes interval initially for 45 minutes and latter 5 minutes, the specimen is placed on the Vicat's apparatus and the depth of penetration of the needle measured (IS: 4031 Part-5, 1988). The view of consistency test in progress is shown as figure 3(a).Specimen is placed concentrically beneath the Vicat's needle $(1 \mathrm{~mm})$ and the movable rod is lowered until the needle end makes a contact with the Geopolymer paste. Penetration at intervals is recorded until a penetration of $33-35 \mathrm{~mm}$ is experienced and this time is recorded as the initial setting time. The final setting time is determined by using a needle with collared ring at the end and observing its impression on the surface of the paste by its free fall. The time when the collar does not make any impression is noted as the final setting time. The view of setting time test is shown as figure 
3(b).The comparison of the initial and final setting times for varying liquid ratio and varying molarities is presented in figures 4 and 5 respectively.
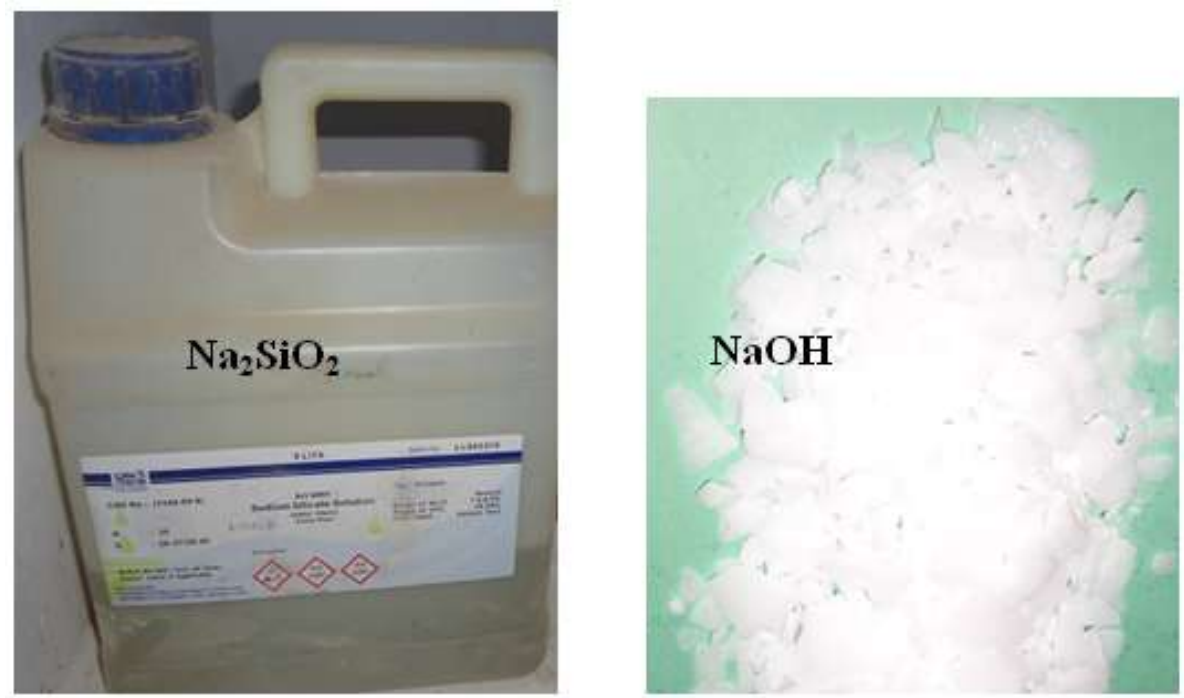

Fig. 1 The constituents of alkaline solution

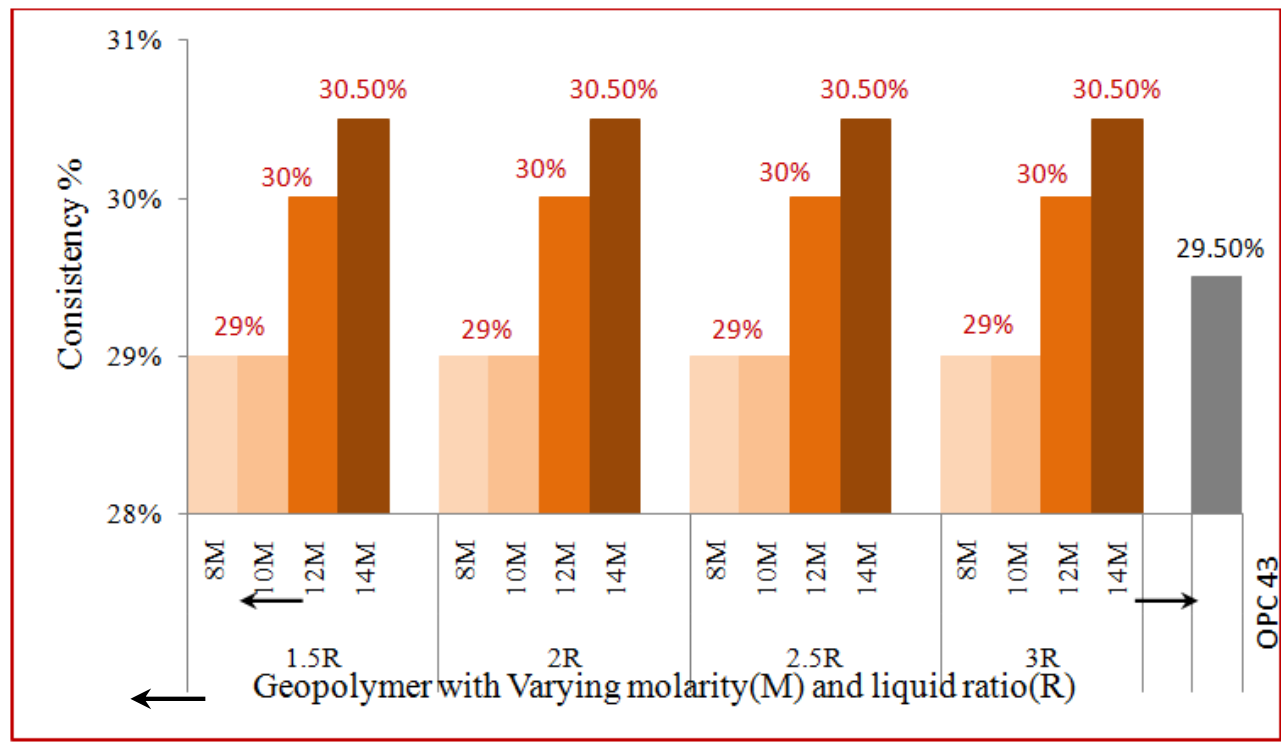

Fig. 2Comparison of Consistency of Geopolymer and Cement paste

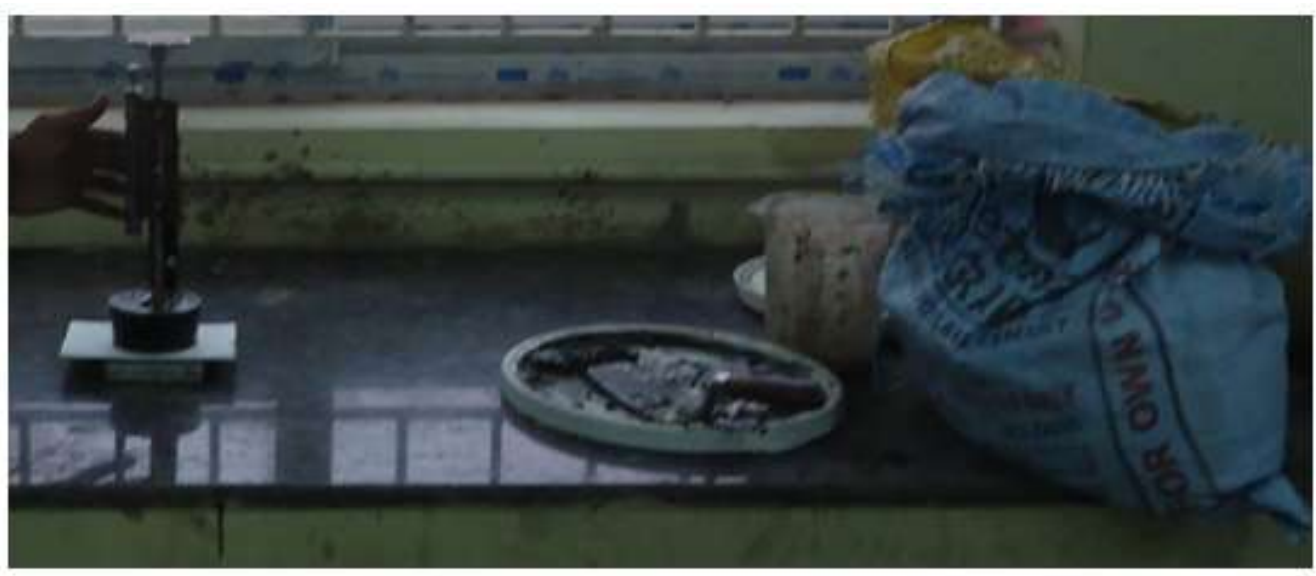

(a) Consistency test 


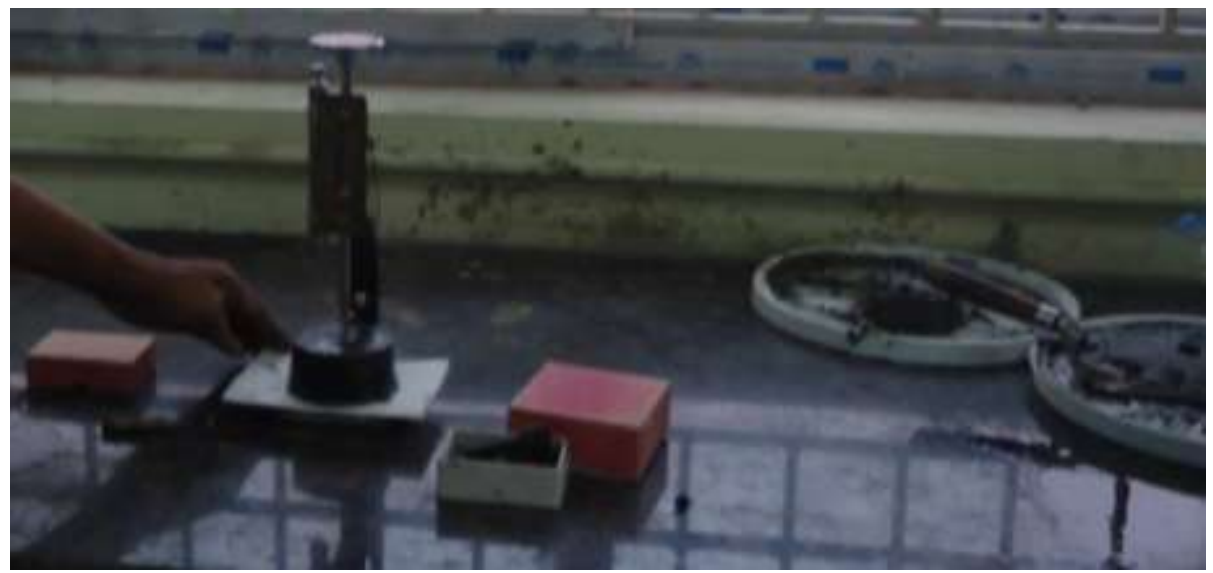

(b) Initial setting time test

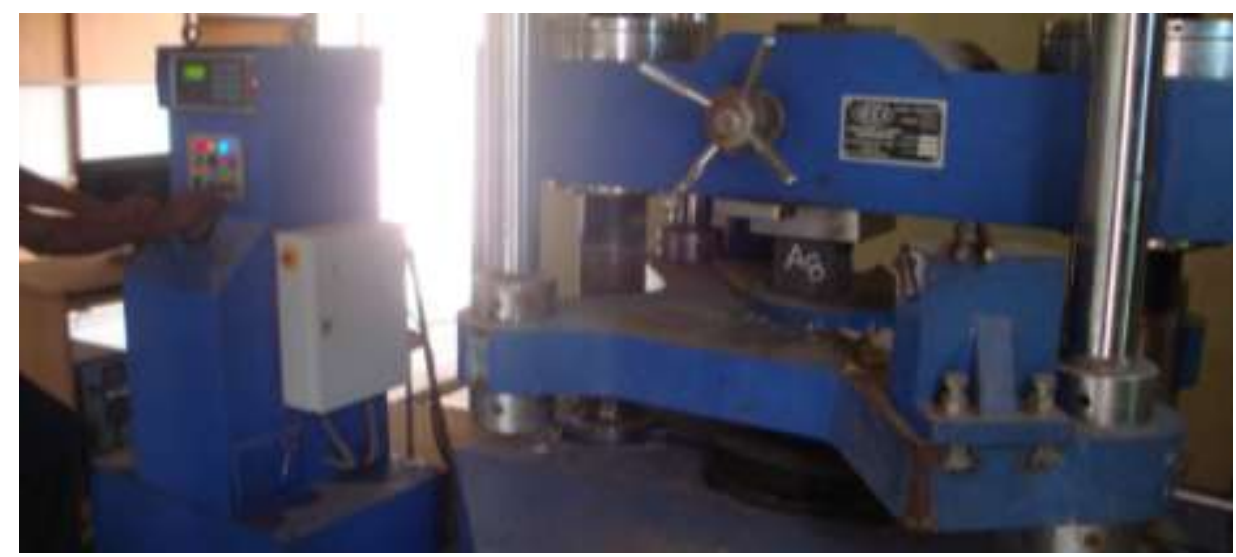

(c) Mortar compressive strength test

Fig 3 Views of various testing
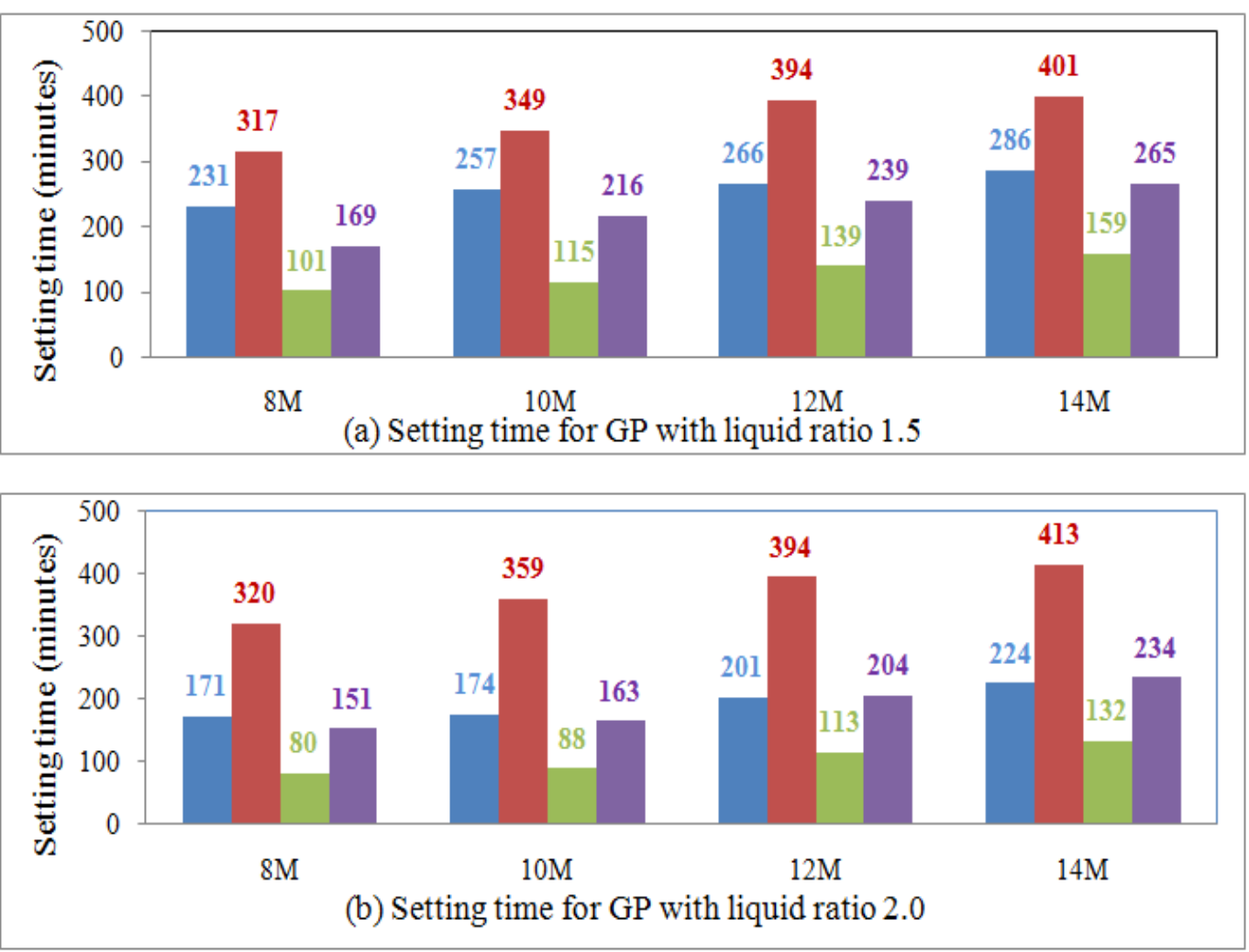

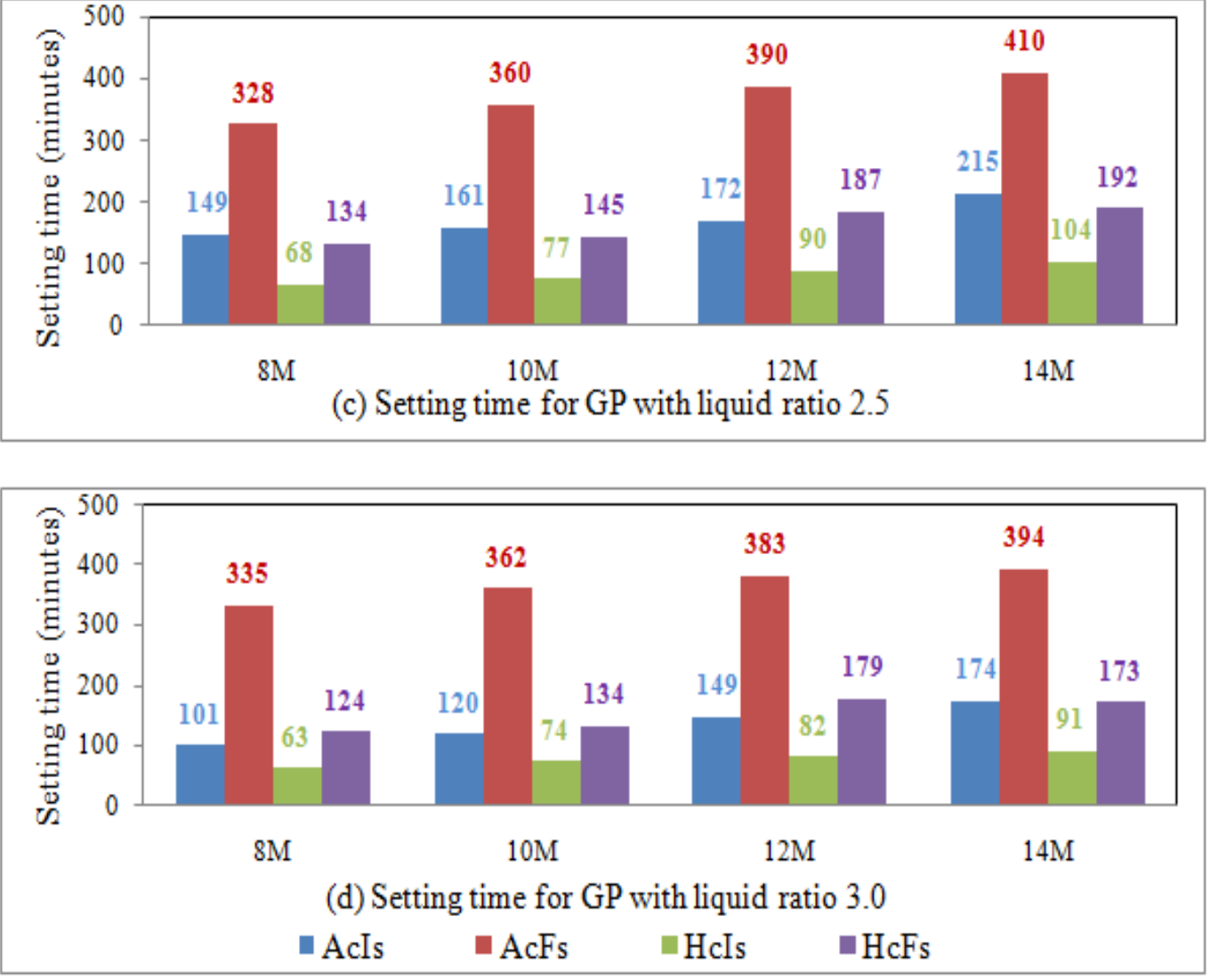

(A-Ambient; H-Hot; I-Initial; F-Final; c-curing; s-setting time)

Fig. 4Comparison of setting time for varying molarity of $\mathrm{NaOH}$ w.r.to liquid ratio
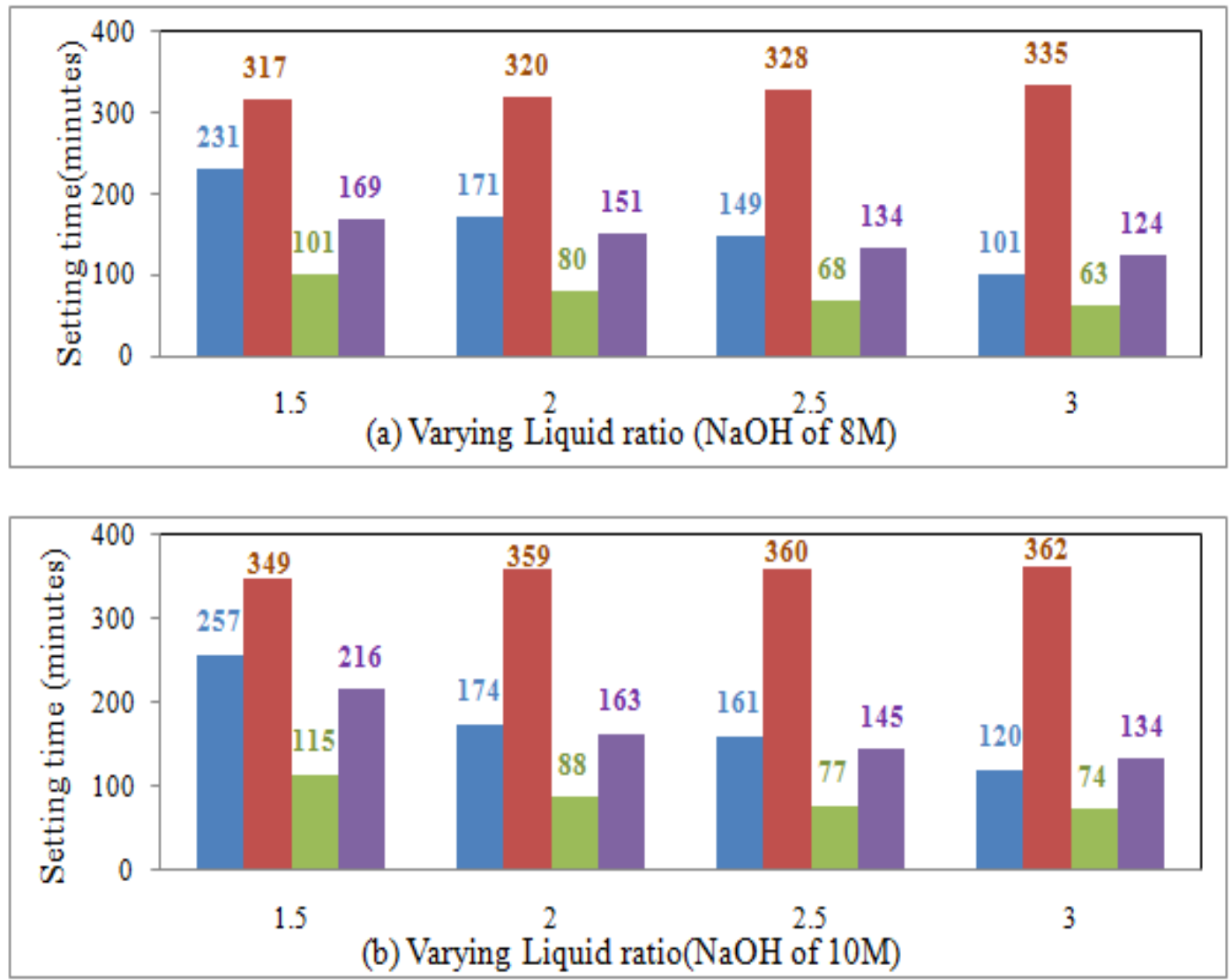

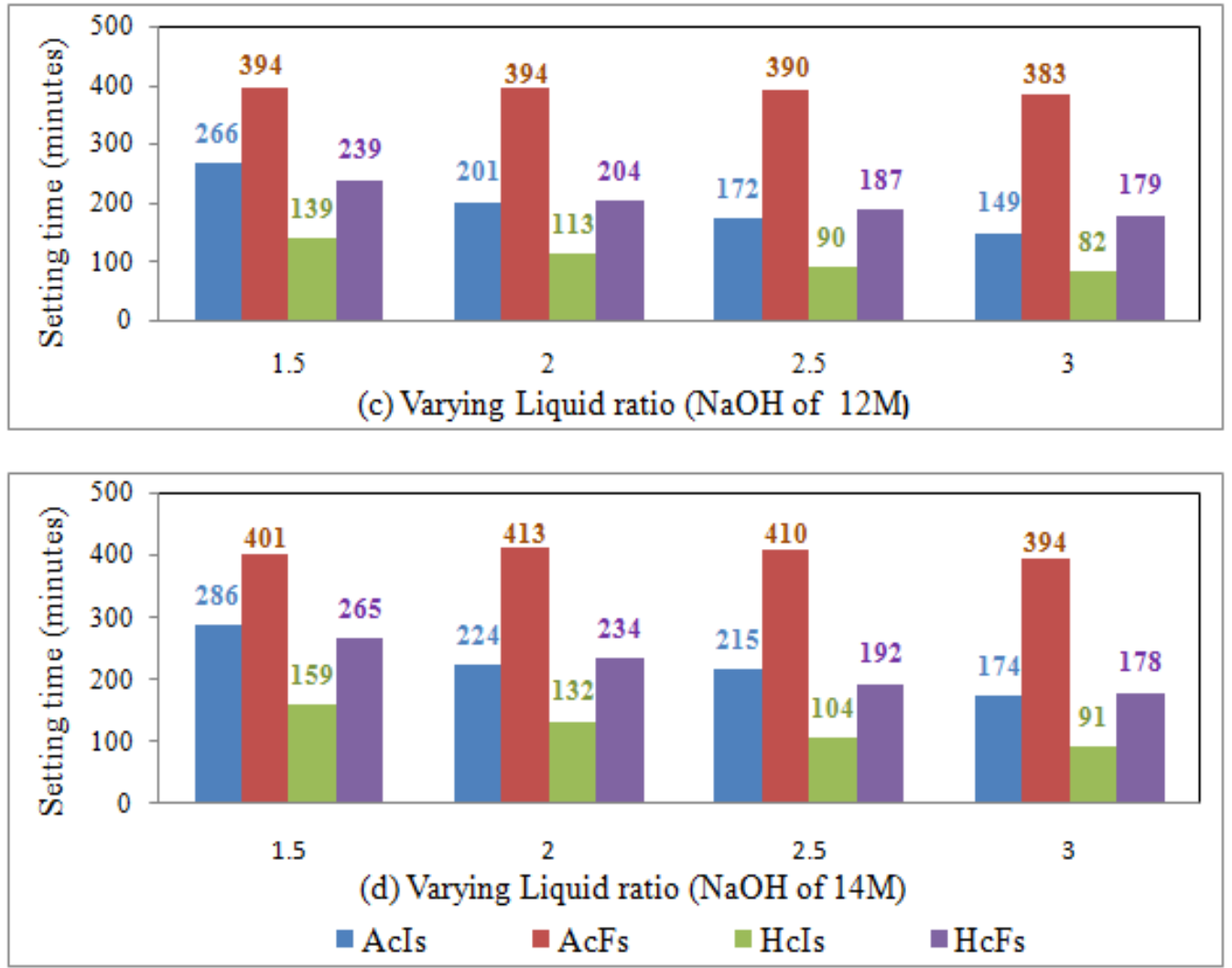

(A-Ambient; H-Hot; I-Initial; F-Final; c-curing; s-setting time)

Fig.5Comparison of setting time for GP paste of varying Liquid ratio w.r.to molarity

\section{Mortar Compressive Strength}

About 555 grams of standard sand and 185 grams of flyash are taken and mixed with alkaline solution (one fourth of the consistency plus $3 \%$ by combined weight of sand and flyash). The mortar is then filled into the $70.7 \mathrm{~mm}$ size cube moulds and compacted. After 24 hours of casting, one set of specimens are kept for hot curing at $65^{\circ} \mathrm{C}$ in an oven for 24 hours and another set of specimens under ambient curing at room temperature. Totally about 32 mixes of GPC and 3 mixes of OPC are considered. The cubes are tested as shown in figure 3(c) in 3, 14 and 28 days appropriately. In parallel, mortar compressive strength based on conventional 33, 43, and 53 grades OPC is also obtained. The test results are presented and compared in figure 6.

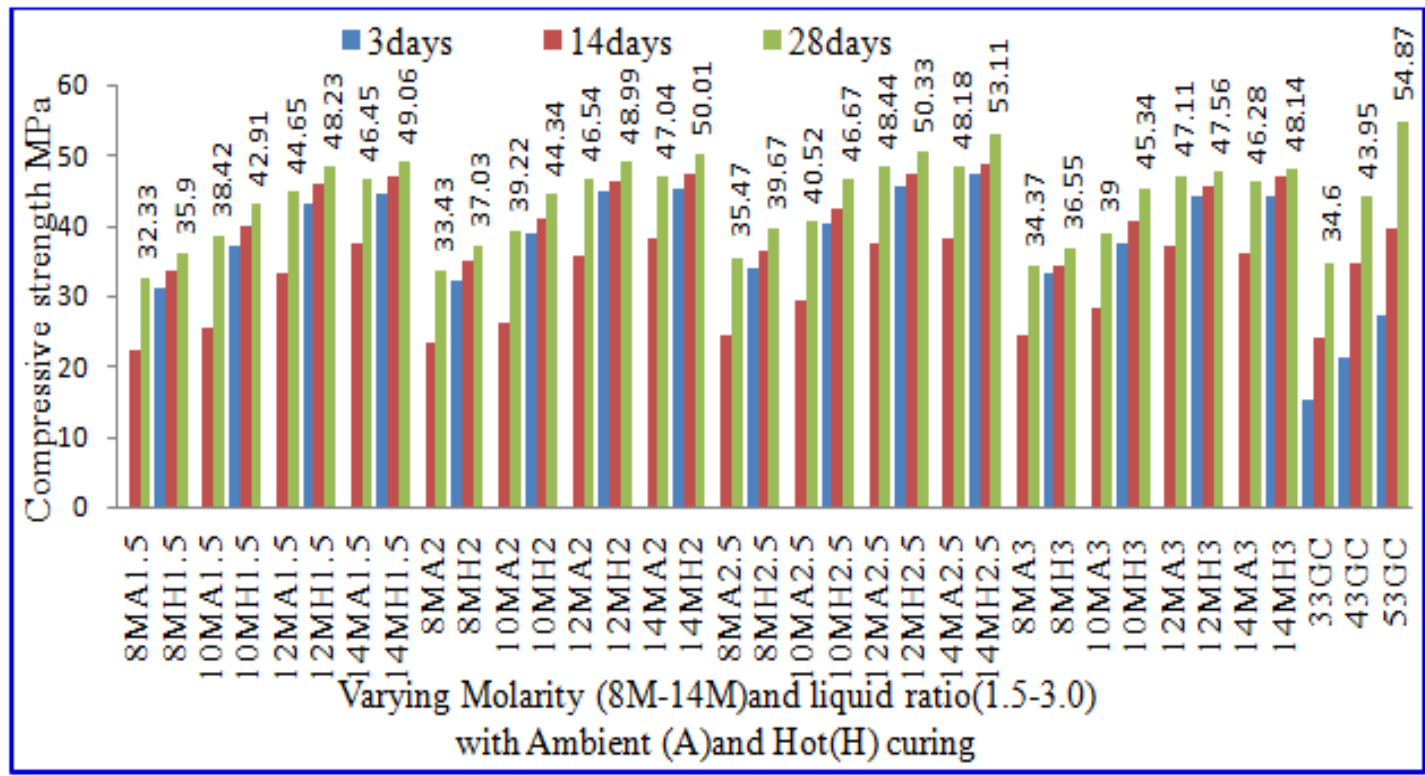

Fig.6Comparison of mortar compressive strength of geopolymer and cement 


\section{Normal consistency}

\section{Discussion of Test Results}

The standard consistency of cement paste is only $29.5 \%$ and that of flyash paste is $29 \%$ for both $8 \mathrm{M}$ and $10 \mathrm{M}$ based. The consistency of flyash based geopolymer paste increased as $30 \%$ for $12 \mathrm{M}$ and $30.5 \%$ for $14 \mathrm{M}$ based ones. This variation is same for all liquid ratios (1.5-3.0). The $85 \%$ of the normal consistency is found adequate for making paste for the setting time test.

\section{Setting time for varying liquid ratios with constant molarity of $\mathrm{NaOH}$}

For the $8 \mathrm{M}$ and $10 \mathrm{M} \mathrm{NaOH}$ based GP, in case of ambient curing, the initial setting time gradually decreases for the increase in the liquid ratio whereas the final setting time increases with a marginal difference. But in the case of hot curing, both the initial and final setting time gradually decrease for the increase in the liquid ratio. For 12 and 14 molar $\mathrm{NaOH}$ based GP, in case of ambient curing, the initial setting time gradually decreases for the increase in the liquid ratio whereas the final setting time is almost same for all the liquid ratios. But for hot curing, both the initial and final setting time gradually decrease for the increase in the liquid ratio.

\section{Setting time for GP paste of varying molarity of $\mathrm{NaOH}$ with constant liquid ratio}

For liquid ratio 1.5 , in case of ambient curing, the initial setting time gradually increases for the increase in the molarity whereas the final setting time increases but significantly. It is also similar in case of hot curing; both the initial and final setting time gradually increases for the increase in the molarity.For liquid ratios 2.0-3.0, in case of ambient curing and hot curing, both the initial and final setting time gradually increase for the increase in the molarity.

\section{Mortar compressive strength}

For hot curing, the compressive strength of mortar increases for increase in the molarity of $\mathrm{NaOH}$ up to liquid ratio of 2.5 and slightly reduces for ratio 3.0. But the rate of increase is more upto molarity $12 \mathrm{M}$ and liquid ratio 2.5 compared to molarity $12 \mathrm{M}$ and ratio 3.0 respectively. The difference in the compressive strength between 3 and 28 days is from $10 \%$ to $16 \%$. This difference is more for lower molarity and less for higher molarity irrespective of the liquid ratios considered. The maximum 28 day compressive strength is achieved from the hot cured samples with $14 \mathrm{Molar} / 2.5$ liquid ratio as $53.1 \mathrm{MPa}$ for which the corresponding 3 day strength is $47.3 \mathrm{MPa}$. In case of ambient curing, the three days strength is not achieved for all the 16 cases and the 14 day strength is always less compared to corresponding hot cured specimens. The maximum 28 day compressive strength is achieved from the ambient cured samples with $14 \mathrm{M} / 2.5$ liquid ratio as $48.2 \mathrm{MPa}$ for which the corresponding 14 day strength is $38.3 \mathrm{MPa}$. The maximum compressive strength is more for hot cured samples by $10 \%$ compared to ambient cured ones.

\section{Conclusion}

- The consistency of geopolymer is proportional to the molarity of $\mathrm{NaOH}$ and independent of the alkaline liquid ratio.

- The standard consistency of geopolymer increases with increase of molar concentration.

- The $85 \%$ of the normal consistency is adequate for making paste for the setting time test.

- For ambient curing, the initial setting time gradually decreases upto $10 \mathrm{M}$ solution based GP for the increase in the liquid ratio whereas the final setting time increases with only a marginal difference.For $12 \mathrm{M}$ and $14 \mathrm{M}$ $\mathrm{NaOH}$ solution ones, the initial setting time gradually decreases for the increase in liquid ratio whereas the final setting time is almost same for all ratios. For hot curing, both the setting time gradually decrease for the increase in the ratio.

- In case of ambient curing, the 3day strength is not achieved for all the 16 cases and the 14 day strength is always less compared to that corresponding to hot cured specimens.

- The compressive strength increases for hot curing, for increase in the molarity of $\mathrm{NaOH}$ up to liquid ratio of 2.5 and slightly reduces for ratio 3.0. But the rate of increase is more upto molarity $12 \mathrm{M}$ and liquid ratio 2.5 compared to molarity $12 \mathrm{M}$ and ratio 3.0 respectively.

- The difference between $3^{\text {rd }}$ and $28^{\text {th }}$ day strength varies from $10 \%$ to $16 \%$ and is more for lower molarity and less for higher molarity irrespective of the liquid ratios considered.

- The maximum 28 day compressive strength is achieved from the hot cured samples with 14Molar/2.5 liquid ratio and is $10 \%$ more compared to ambient cured ones. 


\section{Reference}

[1]. Anjan Chatterjee K (2010). Indian Flyashes, Their Characteristics and Potential for Mechano-Chemical Activation for Enhanced Usability, Proceedings of the second International Conference on Sustainable Construction Materials and Technologies, Universita Politecnica delle Marche, Ancona, Italy, I ( ) :41-51.

[2]. Ashley Russell Kotwal, Yoo Jae Kim, Jiong Hu and Vedaraman Sriraman (2015). Characterization and early age physical properties of ambient cured geopolymer mortar based on class C flyash, International Journal of Concrete Structures and Materials, 9(1): 3543.

[3]. Djwantoro Hardjito, Chua Chung Cheak and Carrie Ho Lee Ing (2008). Strength and setting times of low calcium flyash-based geopolymer mortar, Modern Applied Science, 2(4): 3-11.

[4]. IS: 3812-1981. India Standard Specification for Flyash for use of Pozzolana and Admixture, Bureau of Indian Standards, New Delhi, India.

[5]. IS:4031(Part-4)-1988 (Reaffirmed-2005). Methods of physical tests for hydraulic cement: Part 4 Determination of consistency of standard cement paste,Bureau of Indian Standards, New Delhi, India.

[6]. IS: 4031(Part-5)-1988 (Reaffirmed-2000). Methods of physical tests for hydraulic cement: Part 5 Determination of initial and final setting times, Bureau of Indian Standards, New Delhi, India.

[7]. Joseph Davidovits (1994). Properties of geopolymer cements, Proceedings, Proceedings of the First International conference on Alkaline cements and concretes, Scientific Research Institute on Binders and Materials, KIEV State Technical University, Kiev, Ukraine, pp.131-149.

[8]. Joseph Davidovits (2011). Geopolymer Chemistry and Applications, 3rd edition, Institut Géopolymère, 16-Rue Galilée, F-02100 Saint-Quentin, France.

[9]. Mallikarjuna Rao G and Gunneswara Rao T. D (2015). Final Setting Time and Compressive Strength of Flyash and GGBSBased Geopolymer Paste and Mortar, Arabian Journal for Science and Engineering, 40(11):3067-3074.

[10]. Rajamane NP and Jeyalakshmi R (2014). Quantities of Sodium Hydroxide Solids and Water to Prepare Sodium Hydroxide Solution of Given Molarity for Geopolymer Concrete Mixes, Technical Paper, ICI Update, Aug - Sep 2014, pp. 04-08.

[11]. Rangan BV (2008). Flyash based geopolymer concrete, Research Report GC4,2008, Engineering Faculty, Curtin University of Technology, Perth, Australia.

[12]. Shankar Sanni and Khadiranaikar RB (2012). Performance of geopolymer concrete under severe environmental conditions, International Journal of Civil and Structural Engineering,3(2):396-407.

[13]. Shetty MS. Concrete Technology-Theory and Practice, Chand and Company Ltd., New Delhi, 2009.

[14]. Yellaiah P, Sanjay Kumar Sharma and Gunneshwara Rao TD (2014).Development of flyash based Geopolymer behaviour of Fly Cement, Journal on Today's Ideas-Tomorrow's Technologies, 2(1):1-9. 